\title{
A Study on the Translation Strategies of Commercial Advertisement from the Perspective of Intercultural Communication*
}

\author{
Yuan Wang \\ Xi'an Fanyi University \\ Xi'an, China 710105
}

\begin{abstract}
With the development of commodity economy and the increase of economic and trade exchanges between different countries, the translation of commercial advertisement has become one of the important factors that directly affects the economic benefits of commodities. Therefore, in the process of promoting commodities, the translation of commercial advertisement is of vital importance. Like any other kind of translation, the translation of commercial advertisement is also a kind of intercultural communication activity, and cultural factors must be taken into consideration. Therefore, it is necessary to study the translation strategies of commercial advertisement in intercultural communication. This paper attempts to explore the effective translation strategies of commercial advertisement in the intercultural context from the perspective of intercultural communication.
\end{abstract}

Keywords-intercultural communication; commercial advertisement; translation strategy

\section{INTRODUCTION}

With rapid development of the commodity economy, advertisement has entered thousands of households and penetrated into all aspects of people's lives with the help of various media forms. Commercial advertisements in intercultural communication originate from different cultural environments, and their commodities also live and grow in the same or different cultural environments, so it is restricted by cultures while spreading and promoting cultures themselves. Therefore, in the process of promoting commodities, cultural factors must be taken into account in the translation of advertisements, which not only caters to the psychology of consumers, but also does not violate the national orthodox cultures or regulations. Commercial advertisement is characterized by accuracy, flexibility, innovation, simplicity and clarity. In order to make the translation of commercial advertisement not only conform to the characteristics of commercial advertisement, achieve the effect of the original language, but also transfer the original cultural information naturally, faithfully and accurately, and let customers willingly accept the information of the product

*Fund: The phased achievement of the scientific research project of Xi'an Fanyi University in 2019: A Study on the C-E Translation Strategies of Commercial Advertisement from the Perspective of Intercultural Communication (19A02) and producers happily obtain the ideal economic benefits, it is necessary to study the translation strategies of commercial advertisement in intercultural communication. It will better help advertisers to produce the translation texts of commercial advertisements that meet the requirements of the target language and cultural habits, and ultimately achieve the effect of promoting commodities.

\section{INTERCULTURAL COMMUNICATION AND TRANSLATION OF COMMERCIAL ADVERTISEMENT}

Like any other kind of translation, the translation of commercial advertisement is also a kind of intercultural communication activity.

First of all, any activity has its own purpose, and the translation of commercial advertisement is no exception. The only purpose of the translation of commercial advertisement is to convey the product information to consumers in the target language, take consumers as the center, give them what they want so as to arouse their interests and promote their purchase actions. It can be seen that whether or not the translation of commercial advertisement can achieve the expected function (promotion function) in the cultural environment of the target language largely depends on whether all aspects of the translation can be understood, recognized and accepted by the target language readers.

Secondly, translator will face the target readers whose cultural backgrounds are completely different from that of the source readers, so the first thing for translator is the acceptability of target readers to the advertisements, that is to say, how to cross the cultural gap and convey the intention of the advertiser to readers in different social backgrounds is the first problem for translator. This determines the nature of intercultural communication in the translation of commercial advertisement.

It can be seen that cultural differences have a great influence on the translation of commercial advertisement, so it is very important to understand these differences for the translation of commercial advertisement. The translation of commercial advertisement is mainly read by ordinary people, not scholars, so different national psychologies, values and aesthetic viewpoints caused by cultural differences will affect the understanding and effect of the translation of 
commercial advertisement. In order to achieve the purpose of advertisement, it is necessary to decode the culture when the translation of commercial advertisement with unique cultural characteristics of one country enters into the other country, so as to make the translation of commercial advertisement be good for the target readers. The good translation of commercial advertisement conforms to cultural habits of the target language, arouses pleasant association of the product among the target language readers (consumers), and finally realizes the promotion purpose; however, the translation of commercial advertisement that violates cultural habits of the target language is difficult to be accepted by the target language readers, and even makes cultural errors in specific occasions, so as not to realize the promotion of advertising. Therefore, translators are required to master as much intercultural communication knowledge as possible, accurately grasp the cultural differences between source language and target language, and make the translation conform to the characteristics of the target language. Only in this way can avoid or minimize mistranslation, and successfully complete the intercultural communication activity.

\section{TRANSLATION STRATEGIES OF COMMERCIAL ADVERTISEMENT FROM THE PERSPECTIVE OF INTERCULTURAL COMMUNICATION}

Advertising language is a kind of refined, lively, implied, expressive and inspiring language. The translation of commercial advertisement requires accurate expression of the source language, and cannot mechanically copy the translation of dictionary. Therefore, the translation of commercial advertisement should be flexible, innovative, concise, and in line with national conditions, so that customers are willing to accept the product information. The translation should not only convey the original cultural information naturally, faithfully and accurately, but also conform to the characteristics of the advertisements, so as to achieve the ideal effect and obtain the ideal economic benefits. Here are six strategies available in the translation of commercial advertisement.

\section{A. Literal Translation}

Literal translation is the oldest translation strategy, which plays an important role in the translation of commercial advertisement. Most of the advertisements are declarative, it gives readers the impression that it is concise and natural, which is exactly the artistic conception that literal translation pursues. Literal translation is the translation of words or phrases corresponding to the target language. The form and structure of the translation are required to be consistent with the source language as much as possible, so as to effectively express the meaning and reflect the style of the source language.

For example, "典雅大方 (elegant and graceful)"; "汰渍到, 污垢逃 (Tide's in, dirt's out)"; "畅销全球 (sell well all over the world)"; "what a good time for a good taste of Kent (健牌香烟 其味无穷、其乐无穷)"; "Double delicious, Double your pleasure (双份美味, 双份愉悦); "Coca- Cola is it (还是可口可乐 好)"; "My Paris is in a perfume (巴黎恰在香水中)"; "Kiss your coughs goodbye " (an advertisement of a new cold medicine) is translated as "一吻去感冒". This advertisement concisely and vividly summarizes the function of this medicine, and the expression is vivid and makes people can't help but want to read more.

\section{B. Free Translation}

The translation of advertisement is a kind of practical translation, with the basic purpose of conveying information, and the function of arousing consumers' buying desire. It should adopt a goal orientation strategy, and focus on the audience effect of the target language. Therefore, in order to convey the original information accurately, free translation can be adopted, the form of expression can be reorganized without sticking to the original.

For example, the translation of advertisement of Colgate (a toothpaste brand), "既洁齿, 又清气 (cleans your teeth while it cleans your teeth)", reorganizes the expression form in order to transmit the original information accurately; the translation of "随意少酌 (light cracks are ready on request)" also reorganizes the expression form in order to transmit the original information; the translation of "交货及时 (timely delivery guaranteed)" makes supplements and additions in order to enhance the tone of the original information; "If you're doing business in the Philippines. It pays to get the pick of the cross. (在菲律宾从事事业, 保管发财。)" This advertisement expresses that a bank persuades the business people to establish business relationship with it. The literal meaning of the main sentence is "great harvest can be obtained", but in translation, it should be translated into "keeping and making money" according to the original meaning; China's "白象" (a brand) has been translated into "white elephant", which is in an awkward situation abroad. Although Chinese regard "elephant" as a symbol of auspiciousness and like the scene of "all kinds of renewal", white elephant is a big and useless thing in English speaking countries, so it might as well be translated into "Silver Elephant".

\section{Corresponding Translation (Structure-borrowing)}

The Corresponding translation (Structure-borrowing) is to apply the inherent mode of Chinese or English, and to translate the advertising language on the basis of not destroying the original effect of the advertisement. Due to the differences between Chinese and English cultures, coping and imitating the sentence structure and expression way corresponding to Chinese or English to the greatest extent can make the translation conform to the psychology of consumers, respect the cultural tradition and language expression habit of the recipient language, and maintain the image of the product. In the process of translation, the successful advertising styles, poems and proverbs in English or Chinese can be copied or imitated.

These advertisements use idioms inherent in Chinese or English cultures, which are concise, comprehensive and well-known. They make consumers feel more familiar when they read them. Thus, it conveys the cultural connotation of the source language, and enhances the appeal of 
advertisements. In Chinese or English advertisements, there are many fixed expressions or meanings, which are the same or roughly the same in form or content, such as the four character case, etc., which can also be directly translated.

For example, "百闻不如一尝 (an advertisement of Zhejiang Cereals, Oils \& Foodstuffs Import \& Export Co., Ltd.)" is translated as "Tasting is believing." The structure of a famous English idiom is used in the translation, which is "Seeing is believing". In the process of translation, the word "seeing" is changed, which has a true meaning and the effect is similar to the original. Some other advertisements also use this idiom, such as Shanghai TV, Xihu TV, Bili Slimming Cream. "今日的风彩, 昨夜的绿世界 (Give me Green World. Or give me yesterday.)" The translation is based on the famous speech of Patrick Henry, a famous American politician during the revolutionary war, "Give me liberty. Or give me death." It was the battle trumpet that inspired people at that time. The English translation of "绿世界" advertisement imitates this famous sentence, and retains the original repeated technique of "Give me... Or give me...", thus forms a dual sentence pattern, indicating the significance of contrast and emphasis. The trade name "Green World" replaces "freedom", and "yesterday" replaces "death". It can't help but remind people that, even if the death of youth is as terrible as death, the "green world" will let you say goodbye to yesterday and give you a new self, give you a real free youth; The translation of baby powder advertisement "Like daughter, like mother." uses the pattern of the English idiom "Like son, like father." The translation of cigarette advertisement "To smoke or not to smoke, that is a question." uses the pattern of Shakespeare's famous sentence "To be or not to be, that is a question."; "宁可食无肉, 不可居无 竹叶青。(an advertisement of a kind of liquor)" is translated as "Better a dinner where there Zhuyeqing is, than a stalled ox and Zhuyeqing there with." There is an English proverb, "Better a diner of hers where love is, that a stalled ox and had there with." When this proverb is applied, the original "fat ox" is kept, and it cleverly replaces "love" with "Zhuyeqing (brand mane of the liquor)", makes the translation more infectious, and renders the charm and function of the liquor.

\section{Rhetoric}

In the process of translation, rhetoric is used to make the translation lively and vivid, so as to induce consumers to enter the wonderful commodity world and achieve publicity effect. Rhetoric can be metaphor, personification, euphemism, parallelism, repetition, alliteration and final rhyme, and other forms of rhetoric, such as pun, palindrome, contrast, metonymy, syllepsis, etc.

For example, "柔软迷人, 色泽悦目 (an advertisement of hair cream )" is translated as "soft, enchanting and shining color". Metaphor is used in this advertisement to explain the original thing more concretely and vividly; "一册在手, 纵览全 球 (an advertisement of magazine)" is translated as "The global brands you the world in a single copy." The personification is used in this sentence to endow the commodity life, and give the consumer a kind of cordiality; " 人戴'梅花', 准时乐道 (an advertisement of watch)"is translated as "Give the Plum to all and to all a good time." Repetition is used in this translation. "To all" is said that the watch has various styles, and is suitable for the needs of different customers. The translation has beautiful rhythm and strong feelings, and gives consumers a strong appeal. Pun is also used in this translation. "A good time" can refer to not only the watch "keep a good time", but also the wearer "have a good time". There is another advertisement translated with the final rhyme, "百年老店, 领先二十年 (a hundred years old but still 20 years old)", the final rhyme "old" is cleverly used in the translation, which makes the language rhythmic, pleasant and easy to remember.

\section{E. Cultural Translation}

Due to cultural differences, the expressions of Chinese and English are not the same. When translating advertisements, cultural differences need to be considered. Cultural transformation should be done well in order to repair and transform the differences in the translation. There are some Chinese or English advertisements that express the same concept from the opposite angles. Due to the opposite angles and different expression forms, adaptation should be made when translating advertisements between two languages.

For example, "年终大甩卖 (year-end sale)"; "6 折大减价 (40\% discount/off)". In the above examples, "年终大甩卖" is not translated word for word; "6 折大减价" is translated into "40\% discount" according to the English custom; "With the winter coming in, it's time to buy warm clothes. (冬天到了, 是 买寒衣的时候了。)" The translation does not translate "warm clothes" into "保暖服", but according to the habits of the target language, the translation is carried out from different perspectives according to different language contexts.

\section{F. Creative Rewriting}

Some translations of advertisements are wordy if literal translation method is used, and can not achieve the effect if free translation method is used. In view of this, the strategy of creative rewriting can be used. Creative rewriting is to change the style of advertisement in order to realize its function. It must be pointed out that rewriting does not mean to create what does not exist or something new, it also does not mean to completely throw away the original text. Creative rewriting gives full play to advantages of the target language and recreates in a vivid and appropriate language. For example,

\section{"Butlin's - the right choice}

Don't labour the point, or be conservative in your choice, or liberal with your money.

\section{Come to Butlin's for the real party}

\section{Great Party Ahead."}

This is an advertisement of a tourism company. "Labour", "Conservative" and "Liberal" are the names of the three major political parties in the UK. While "labor the point", "be conservative", and "be liberal with money" can be translated as "detailed explanation", "being conservative in 
making choices" and "spending a lot of money" separately. Obviously, this English advertisement can't play its due effect in Chinese, but it can achieve the expected function with the sentence pattern of parallelism. The translation is as follows: "布特林旅游公司——你的正确选择。不要劳烦讲个没完; 不要保守, 也别犹豫; 不要放任自由地花钱。到布特林旅游公司参加 实实在在地聚会吧, 盛大的聚会也等着你! "

\section{CONCLUSION}

High quality commercial advertisement effectively affects people's consumption decisions. When commercial advertisement spreads from one culture to the other, how to win the identity of the target language users is the main task of translation. Paying attention to cultural differences and giving full play to the translator's subjectivity in literal translation, free translation, corresponding translation (structure-borrowing), rhetoric, cultural translation and creative rewriting are important factors in the translation of commercial advertisement from an intercultural perspective.

\section{REFERENCES}

[1] Jiang Lei. "On the Translation of Commercial Advertisements." Chinese Translators Journal, 1994, (5):38-41.

[2] Jin Huikang. Translation In Intercultural Communication. Beijing: China Translation Corporation, 2003.

[3] Lang Shanshan. "A Study on the Translation of Commercial Advertisements from the Perspective of Intercultural Communication." China Training, 2016, (10):276-277.

[4] Liu Fagong. "On Principle of Chinese-English Translation of Advertising Language." Foreign Languages and Their Teaching, 1999, (3):41-43.

[5] Zhang Lixia. "On the Differences and Blending of Chinese and Western Cultures from the Perspective of Advertising Language." Foreign Languages and Their Teaching, 2000, (11):61-62.

[6] Editorial Office of Chinese Translators Journal. A Collection of Chinese English Translation Skills. Beijing: China Translation Corporation, 1997. 